UDC 542.06; 543.544.5.068.7; 579.674

DOI: $10.21668 /$ health.risk/2020.1.04.eng

\title{
STUDYING THE CONTAMINATION OF TEA AND HERBAL INFUSIONS WITH MYCOTOXINS (MESSAGE 2)
}

\author{
M.G. Kiseleva, Z.A. Chalyy, I.B. Sedova, L.P. Minaeva, S.A. Sheveleva \\ Federal Research Centre of Nutrition, Biotechnology and Food Safety, 2/14 Ust inskiy lane, Moscow, 109240, \\ Russian Federation
}

The authors performed screening of a wide range of mycotoxins by ultra-high-performance liquid chromatography combined with tandem mass spectrometry (UHPLC-MS/MS) in various tea products distributed on the RF market. Samples were selected in retail outlets and obtained from wholesalers. Seventy-seven tea samples were examined: 54 out of them were Camellia sinensis tea, not packed (semi-finished product) and packed; 23 were mono- and multi-component herbal tea. The analytes were 29 mycotoxins including regulated in food products (aflatoxins, ochratoxin A, deoxynivalenol, fumonisins, T-2 toxin and zearalenone), their derivatives and structural analogues (A and B trichothecenes, structural analogues of zearalenone); emergent mycotoxins (sterigmatocystin, mycophenolic acid, moniliformin, enniatins, beauvericin and Alternaria toxins). C. sinensis tea samples, both green and black, were the least contaminated. In contrast, multi-component herbal tea samples tended to be simultaneously contaminated with several mycotoxins (over five) both regulated in food products and emergent ones. Beauvericin, mycophenolic acid and enniatin B were the most frequently detected. Toxigenic properties of mixed tea microflora were examined in vitro. Model experiments were carried out on a substrate consisting of $C$. sinensis green tea leaves in the absence of any growth factors. Mixed mycoflora from tea, which contained potentially toxigenic species of mold species proved to be capable to simultaneously produce substantial quantities of several mycotoxins including emergent ones. Mycotoxins accumulation amounted to 290 and 5,600 $\mu \mathrm{g} / \mathrm{kg}$ of fumonisins B1 and B2 accordingly; $130 \mu \mathrm{g} / \mathrm{kg}$ of zearalenone; $14 \mu \mathrm{g} / \mathrm{kg}$ of sterigmatocystin; $160 \mu \mathrm{g} / \mathrm{kg}$ of alternariol methyl ester. The present survey indicates there is a potential health risk associated with mycotoxins in teas, especially herbal ones. The systematic study of contamination of tea products distributed in the RF with mycotoxins and their producers has been performed for the first time. Long-term monitoring over variety of mycotoxins in this kind of food products is essential for assessing its safety.

Keywords: mycotoxins, emergent mycotoxins, C. sinensis tea, herbal tea, UHPLC-MS/MS, mycotoxins producers, mycotoxins occurrence in vitro.

Mycotoxins (MTs) are secondary metabolites of mold fungi. They are globally recognized food contaminants, which affect its safety for the customers. According to the Food and Agricultural Organization (FAO), approximately $25 \%$ of food and feed worldwide is contaminated with MTs [1]. Toxic fungal metabolites produce a wide range of adverse effects on human health, starting from immune suppression and up to carcinogenesis.
Reduction of risks associated with MTs in food is a vital task of health preservation. To solve it, leading world mycologists and toxicologists adopted the Mycotox Charter (chrter.mycokey.eu) calling for responsibility borne by the present generation for developing and implementing solutions aimed at minimizing MTs exposure worldwide and securing enhanced food safety for future generations [2]. Mold fungi are widely spread and are almost

(c) Kiseleva M.G., Chalyy Z.A., Sedova I.B., Minaeva L.P., Sheveleva S.A., 2020

Mariya G. Kiseleva - PhD in chemistry, Researcher at the laboratory of enzymology of nutrition (e-mail: mg_kiseleva@ion.ru; tel.: +7 (495) 698-53-65; ORCID: https://orcid.org/0000-0003-1057-0886).

Zakhar A. Chalyy - Laboratory Assistant Researcher at the laboratory of enzymology of nutrition (e-mail: brew@ion.ru; tel.: +7 (495) 698-53-65); ORCID: https://orcid.org/0000-0002-9371-8163).

Irina B. Sedova - PhD in biology, Senior researcher at the laboratory of enzymology of nutrition (e-mail: isedova@ion.ru; tel.: +7 (495) 698-53-65; ORCID: https://orcid.org/0000-0002-6011-4515).

Lyudmila P. Minaeva - PhD in Technical Sciences, Senior researcher at the laboratory of biosafety and nutrimicrobiome analysis (e-mail: liuminaeva-ion@mail.ru; tel.: +7 (495) 698-53-83; ORCID: http://orcid.org/0000-0003-1853-5735).

Svetlana A. Sheveleva - Doctor of Medical Sciences, Head of the laboratory of biosafety and nutrimicrobiome analysis (e-mail: sheveleva@ion.ru; tel.:+7 (495) 6 98-53-83; ORCID:_https://orcid.org/0000-0001-5647-9709). 
inevitable in plant commodities. Toxins can be produced both during vegetation and after harvesting, at any stage in a technological chain (storage, processing and transportation). Contents of the most hazardous MTs (deoxynivalenol (DON), T-2 toxin, zearalenone (ZEA), ochratoxin A (OTA), aflatoxin B1 (AFL B1), fumonisins (FBs)) in food are regulated in most countries. The Technical Regulations of the Customs Union CU TR 021/2011 “On food products safety"1 and CU TR 015/2011 "On the safety of grains", are the principal regulations in the Russian Federation (RF). There are also about forty state standards and guidelines describing analytical procedures based on up-to-date analytical technologies (ELISA (enzyme-linked immune-sorbent assay), HPLC and HPLC-MS) developed for mycotoxins determination in food.

HPLC-MS/MS provides opportunities for selective and sensitive determination of miltiple contaminants simultaneously. It is widely used for monitoring over broad spectrum of fungal metabolites [3-6]. Their list is being constantly enriched. There are analytical procedures validated for the determination of regulated MTs and their structural derivatives (3- and 15-acetyl deoxynivalenol, nivalenol, fusarenone $\mathrm{X}-\mathrm{DON}$ group (trichothecenes B); HT-2 toxin, T-2 triol, diacetoxyscirpenol - T-2 toxin group (trichothecenes A); aflatoxins B2, G1, G2, sterigmatocystin (STC) - AFL B1 analogues; zeranol, taleranol, $\alpha$ - and $\beta$-zearalenol - ZEA analogues), Alternaria MTs (alternairol $(\mathrm{AOH})$, its methyl ester (AME), altenuene, tentoxin (TEN)), as well as 'emergent' MTs (EMTs: enniatins A and B (Enn A and $B)$, beauvericin (BEA)) [7-10]. The number of surveys concerning the occurrence of nonregulated MTs in plant commodities and food products is increasing. Meanwhile, the toxic effects produced by these MTs and their combinations are explored insufficiently. Data on combined chronic dietary exposure to small doses of MTs are insufficient. This determines the relevance of extensive research on plant products that belong to mass consumption segment including tea.

Traditional $C$. sinensis tea is a popular drink all over the world; it is usually associated with beneficial health effects. However, subtropics favorable for tea cultivating, are also suitable for mold fungi development and toxins production. Concentrations of FBs, OTA, AFLs, ZEA, trichothecenes and citrinin detected in tea were reported at dozens and even hundreds of $\mu \mathrm{g} / \mathrm{kg}$. Literature data on analytical methods used for the determination of MTs in tea, their occurrence and legislation were summarized in [11]. At present, only AFL B1 or total AFLs in tea are subject to regulation in some countries. Maximum levels (MLs) for these toxins were set in Argentina, India, Sri-Lanka, Japan and China. MLs vary from 5 to $30 \mu \mathrm{g} / \mathrm{kg}$. Five $\mu \mathrm{g} / \mathrm{kg}$ is set as ML for AFL B1 in dry tea at in the CU countries (Russia, Kazakhstan, Belorussia, Armenia, Kirgizia) (CU TR 021/2011 ${ }^{1}$ ).

Herbal teas are becoming increasingly popular. They often contain medicinal herbs (mint, chamomile, nettle, liquorice, wild dogrose etc.) and are specified by manufacturers as "health-related products". However, there are reports on the detection of MTs and their producers in foodstuff of herbal origin. AFLs, OTA and Alternaria toxins were detected in herbal food supplements of similar composition [12].

In previous studies, the authors obtained data on the levels and frequency of mold contamination of more than 50 tea samples (black and green $C$. sinensis tea, herbal tea) [13]. The maximum levels of contamination in all Camellia sp. tea samples were due to fungi of the Aspergillus genus, among which the Aspergillus species of the Nigri section dominated. These species were the major fungi found in herbal teas. Alongside Penicillium sp., Alternaria sp., Fusarium sp., and Cladospo-

\footnotetext{
${ }^{1}$ CU TR 021/2011. On food products safety: The Technical Regulations of the Customs Union / approved by the Decision by the Customs Union Commission on December 9, 2011 No. 880. KODEKS: the electronic fund for legal and reference documentation. Available at: http://docs.cntd.ru/document/902320560 (20.11.2019).

${ }^{2}$ CU TR 015/2011.On safety of grains (last edited on September 15, 2017): The Technical Regulations of the Customs Union / approved by the Decision by the Customs Union Commission on December 9, 2011 No. 874. KODEKS: the electronic fund for legal and reference documentation. Available at: http://docs.cntd.ru/document/902320395 (20.11.2019).
} 
rium $s p$. were also detected. Certain species from this group are able to produce toxins. Thus MTs synthesized by those mold fungi can be found in herbal infusions. An issue related to microbiological regulations concerning mold fungi established for tea and the possibility of changing them in order to harmonize national standards with international requirements is being discussed in the RF at present. So far, there has been no full-scale study on the occurrence of wide range of MTs in $C$. sinensis and herbal tea distributed on the RF market. The present research is aimed at filling this gap.

Our research goals were (1) to screen $C$. sinensis and herbal tea for a wide range of MTs: regulated (AFLB1, B2, G1, G2; OTA, DON, FB1, FB2, T-2, ZEA), their derivatives and structural analogues (DAS, T-2 triol, NeoS, HT-2 toxin; 3- and 15-AcDON, NIV, FusX; $\alpha-, \beta-Z E L, \alpha-, \beta-Z A L)$, and emergent MTs (STC, MPA, MO, EnnA and B, BEA, AOH и AME, TEN). (2) To reveal possible correlations between MT contents and fungal contamination of studied tea samples (3) we also examined the toxigenic properties of tea microflora in vitro under conditions as close to real as it was only possible.

Samples: We examined 77 tea samples. 30 samples were semi-finished (not packed) traditional black and green teas (C. sinensis) from six tea-producing regions (Vietnam, India, Indonesia, Kenya, China and Sri-Lanka). They were obtained from wholesalers. 22 samples were traditional packed green and black teas $(C$. sinensis) and teas with additives. Two samples were Pu'er tea. 23 samples were herbal tea: monocomponent ones: Sudan rose (Hibiscus sabdariffa), fermented Ivan-tea (Epilobium angustifolium), thyme (Thymus serpyllum), mint (Menthae piperita) and chamomile (Chamomilae vulgaris) and multi-component ones. The composition of the latter is presented in Table 1.

Methods: 29 MTs were detected by UHPLC-MS/MS consisting of UHPLC Vannquish system (equipped with a binary pump, autosampler, and thermostat) combined to triple quadrupole mass-spectrometer with heated electrospray source TSQ Endura conducted by Xcalibur 4.0 QF2 Software (all Thermo Scientific, the USA).
Table 1

Composition of multi-component herbal tea samples

\begin{tabular}{|c|c|}
\hline $\begin{array}{l}\text { Sample } \\
\text { No. }\end{array}$ & Components \\
\hline 2 & Ivan-tea (E. angustifolium), currant (Ríbes sp.) \\
\hline 8 & $\begin{array}{l}\text { Hawthorn berries (Crataegus sp.), white } \\
\text { mistletoe leaves (Viscum álbum), melilot } \\
\text { (Melilótus officinális), motherwort (Leonu- } \\
\text { rus cardiaca), valerian root (Valeriana } \\
\text { officinalis) }\end{array}$ \\
\hline 9 & $\begin{array}{l}\text { Echinacea (Echinácea purpúrea), origanum } \\
\text { (Origanum vulgáre), brandy mint (Méntha } \\
\text { piperita), nettle (Urtica sp.), thyme (Thymus } \\
\text { serpyllum), chamomile (Chamomilae vulga- } \\
\text { ris), wild rose (Rōsa sp.), sage (Sālvia offici- } \\
\text { nālis), violet (Viola sp.), licorice (Glycyr- } \\
\text { rhíza sp.) }\end{array}$ \\
\hline 10 & $\begin{array}{l}\text { Thyme (Thymus serpyllum), St. John's wort } \\
\text { (Hypericum perforatum) }\end{array}$ \\
\hline 11 & $\begin{array}{l}\text { Chamomile (C.vulgaris), brandy mint } \\
\text { (M.piperita), everlasting leaves (Helichrysi } \\
\text { arenarii), tansy flowers (Tanacetum sp.), } \\
\text { coriander berries (Coriándrum sátivum), } \\
\text { holy-thistle (Sílybum mariánum), mint } \\
\text { (Méntha sp.), melilot (M.officinális), wild } \\
\text { rose berries (Rōsa sp.), inula root (Inula sp.), } \\
\text { hawthorn berries (Crataegus sp.) }\end{array}$ \\
\hline 12 & $\begin{array}{l}\text { Marigold (Bídens tripartita), sarcarolla } \\
\text { (Caléndula sp.), everlasting (Agrimónia eu- } \\
\text { patória), chamomile (C.vulgaris), St. John's } \\
\text { wort (H.perforatum), birch leaves (Betula } \\
\text { pendula) }\end{array}$ \\
\hline 14 & $\begin{array}{l}\text { Ivan-tea (E. angustifolium), cowberry (Vac- } \\
\text { cinium vítis-idaéa) }\end{array}$ \\
\hline 19 & $\begin{array}{l}\text { Ground lemon (Cymbopogon citratus), } \\
\text { lemon myrtle (Backhousia citriodora), gin- } \\
\text { ger root (Zìngiber officināle), licorice root } \\
\text { (G.glábra), dried lemon peel (Cítrus límon) }\end{array}$ \\
\hline 20 & Chamomile (C.vulgaris), mint (Méntha sp.) \\
\hline 36 & $\begin{array}{l}\text { Ivan-tea (E. angustifolium), sea-buckthorn } \\
\text { (Hippóphä̈ sp.) }\end{array}$ \\
\hline 38 & Ivan-tea (E. angustifolium), linden (Tília sp.) \\
\hline
\end{tabular}

Analytes were separated on a reversedphase column Titan C18, 2.1*100 mm, $1.9 \mu \mathrm{m}$ (Supelco, PA, USA), under gradient elution. The mobile phases were constituted of: (A) methanol-water (10/90\% vol.); (B) methanolwater-acetonitrile $(10 / 10 / 80 \%$ vol. $)$. Both 
phases were modified with $1 \mathrm{mM}$ ammonium formate and $0.1 \%$ formic acid. The gradient scheme was as follows: from the start to $1 \mathrm{~min}$. $0 \% \mathrm{~B}$; from 1 to $2 \mathrm{~min}$. - a linear growth to $15 \% \mathrm{~B}$; from 2 to $5 \mathrm{~min}$. - to $30 \% \mathrm{~B}$; from 5 to 13 min.- up to $70 \% \mathrm{~B}$; from 13 to $14 \mathrm{~min}$. $90 \% \mathrm{~B}$; from 14 to $16.5 \mathrm{~min}$. - $95 \% \mathrm{~B}$; up to 17 min. - growth to $100 \% \mathrm{~B}$ and then retention for 3 minutes; from 20 to $20.5 \mathrm{~min}$. a decrease down to $0 \% \mathrm{~B}$; equilibration - until 22 minutes. Mobile phase flow: $0.4 \mathrm{ml} / \mathrm{min}$. The column temperature was set to $30^{\circ} \mathrm{C}$. Injection volume: $2-4 \mu$ l. Run time: 22 minutes. Analytes were detected in the MRM mode. Limit of quantification (LOQ) was determined by $10 \sigma$ criterion. Recovery was determined for spiked green tea. Summarized method parameters are provided in Table 2.

Neat standards of AFL B1, AFL B2, AFL G1, AFL G2, STC, T-2 and NT-2 toxins, DAS, NIV, DON, 3- and 15-AcDON, FusX, FB1, FB2, ZEA, $\alpha-$ and $\beta-Z E L, \alpha-Z A L$, OTA were supplied by Sigma-Aldrich (Russia, Moscow). AOH, AME, BEA, EnnA, EnnB, MPA, MO, NeoS, T-2 triol, TE were obtained from Fermentek (Jerusalem, Israel). Stock standards solutions were prepared in acetonitrile (AFLs, STC, trichothecenes, ZEA and its analogues, OTA, MPA), methanol (Alternaria MTs, Enns, BEA, MPA, MO) or water-acetonitrile

Table 2

HPLC-MS/MS method characteristics summary

\begin{tabular}{|c|c|c|c|c|c|c|c|c|}
\hline No. & MT & $t_{R}, \min$ & Parent ion & $\mathrm{m} / \mathrm{z}$ & $\mathrm{RF}, \mathrm{V}$ & $\begin{array}{l}\text { Daughter ions, } \mathrm{m} / \mathrm{z} \\
\text { (collision energy, } \mathrm{V} \text { ) }\end{array}$ & $\begin{array}{l}\mathrm{LOQ}, \\
\mu \mathrm{g} / \mathrm{kg}\end{array}$ & $\begin{array}{l}\text { Reco- } \\
\text { very, \% }\end{array}$ \\
\hline 1 & $\mathrm{MO}$ & 0.7 & {$[\mathrm{M}-\mathrm{H}]^{-}$} & 97 & 54 & $41 *(12), 80(23)$ & 800 & 76 \\
\hline 2 & NIV & 1.8 & {$[\mathrm{M}+\mathrm{H}]^{+}$} & 313 & 100 & 125 (10), $177(10)$ & 1,000 & 81 \\
\hline 3 & DON & 2.9 & {$[\mathrm{M}+\mathrm{H}]^{+}$} & 297 & 100 & $\mathbf{2 0 3}(\mathbf{1 8}), 231(12), 249(11)$ & 1,250 & 63 \\
\hline 4 & FusX & 3.6 & {$[\mathrm{M}+\mathrm{H}]^{+}$} & 355 & 103 & $175(\mathbf{2 0}), 229(16), 247(12)$ & 100 & 80 \\
\hline 5 & NeoS & 3.9 & {$\left[\mathrm{M}+\mathrm{NH}_{4}\right]^{+}$} & 400 & 79 & $\mathbf{1 8 5}(\mathbf{1 7}), 203(17), 215(18), 305(10)$ & $<10$ & 75 \\
\hline 6 & AcDON & 4.6 & {$[\mathrm{M}+\mathrm{H}]^{+}$} & 339 & 97 & $203(17), 213(18), 231(13)$ & 250 & 94 \\
\hline 7 & T-2 triol & 4.8 & {$\left[\mathrm{M}+\mathrm{NH}_{4}\right]^{+}$} & 400 & 76 & $215(\mathbf{1 0}), 263(13)$ & 250 & 75 \\
\hline 8 & AFLG2 & 6.2 & {$[\mathrm{M}+\mathrm{H}]^{+}$} & 331 & 170 & $189(41), 245(30), 313(24)$ & 4 & 79 \\
\hline 9 & AFLG1 & 6.6 & {$[\mathrm{M}+\mathrm{H}]^{+}$} & 329 & 150 & $200(41), 243(26), 311(21)$ & 4 & 85 \\
\hline 10 & AFLB2 & 6.8 & {$[\mathrm{M}+\mathrm{H}]^{+}$} & 315 & 170 & $243(39), 259(29), 287$ (26) & 4 & 85 \\
\hline 11 & DAS & 6.9 & {$\left[\mathrm{M}+\mathrm{NH}_{4}\right]^{+}$} & 384 & 89 & $247(14), 307(10), 349(10)$ & 20 & 95 \\
\hline 12 & AFLB1 & 7.3 & {$[\mathrm{M}+\mathrm{H}]^{+}$} & 313 & 166 & $213(45), 241(37), 285(22)$ & 4 & 85 \\
\hline 13 & $\mathrm{AOH}$ & 8.0 & {$[\mathrm{M}+\mathrm{H}]^{+}$} & 259 & 100 & $128(44), 184(30), 213(27)$ & 1,000 & 87 \\
\hline 14 & HT-2 & 8.0 & {$\left[\mathrm{M}+\mathrm{NH}_{4}\right]^{+}$} & 442 & 91 & $215(10), 263(10)$ & 500 & 77 \\
\hline 15 & FB1 & 8.0 & {$[\mathrm{M}+\mathrm{H}]^{+}$} & 772 & 217 & $334(40), 352$ (36) & 400 & 44 \\
\hline 16 & $\alpha-Z A L$ & 8.3 & {$[\mathrm{M}+\mathrm{H}]^{+}$} & 323 & 66 & $189(22), 305(10)$ & 125 & 76 \\
\hline 17 & TE & 8.3 & {$[\mathrm{M}+\mathrm{H}]^{+}$} & 415 & 130 & $302(13), 312(19)$ & 4 & 78 \\
\hline 18 & $\beta-Z E L$ & 8.5 & {$[\mathrm{M}+\mathrm{H}]^{+}$} & 321 & 88 & $189(20), 303(10)$ & 1,000 & 88 \\
\hline 19 & MPA & 8.9 & {$[\mathrm{M}+\mathrm{H}]^{+}$} & 321 & 113 & $207(22), 275(16)$ & 50 & 101 \\
\hline 20 & $\alpha-Z E L$ & 9.5 & {$[\mathrm{M}+\mathrm{H}]^{+}$} & 321 & 65 & $189(22), 303(11)$ & 1,000 & 84 \\
\hline 21 & $\mathrm{~T}-2$ & 9.7 & {$\left[\mathrm{M}+\mathrm{NH}_{4}\right]^{+}$} & 484 & 137 & $215(17), 305(13)$ & 10 & 100 \\
\hline 22 & FB2 & 9.7 & {$[\mathrm{M}+\mathrm{H}]^{+}$} & 706 & 150 & $\mathbf{3 1 8}(\mathbf{3 6}), 336(36)$ & 100 & 73 \\
\hline 23 & OTA & 10.4 & {$[\mathrm{M}+\mathrm{H}]^{+}$} & 404 & 123 & $221(35), 239(24), 358(14)$ & 2.5 & 78 \\
\hline 24 & AME & 10.5 & {$[\mathrm{M}+\mathrm{H}]^{+}$} & 273 & 150 & $\mathbf{1 8 5}(\mathbf{4 0}), 199(40), 258(30)$ & 750 & 87 \\
\hline 25 & ZEA & 10.5 & {$[\mathrm{M}+\mathrm{H}]^{+}$} & 319 & 90 & $185(20), \mathbf{2 8 3}(\mathbf{1 0}), 301(10)$ & 150 & 86 \\
\hline 26 & STC & 10.9 & {$[\mathrm{M}+\mathrm{H}]^{+}$} & 325 & 152 & $253(44), 281(36), 310(24)$ & 4 & 78 \\
\hline 27 & EnnB & 15.1 & {$\left[\mathrm{M}+\mathrm{NH}_{4}\right]^{+}$} & 657 & 142 & $196(30), 214(31), 527(27), 640(17)$ & 2.5 & 73 \\
\hline 28 & BEA & 15.5 & {$\left[\mathrm{M}+\mathrm{NH}_{4}\right]^{+}$} & 801 & 215 & $244(32), 262(30), 784(17)$ & 2.5 & 80 \\
\hline 29 & EnnA & 16.2 & {$\left[\mathrm{M}+\mathrm{NH}_{4}\right]^{+}$} & 699 & 255 & $210(24), 228(24)$ & 6 & 92 \\
\hline
\end{tabular}

Note: daughter ions selected for quantitative analysis are given in bold. Method was verified for C. sinensis black tea. 
(50/50 \% vol.) (FB1 and FB2). Stock individual standard solutions were used for the construction of the multi-analyte standard solution. All the standards solutions were stored at $-18{ }^{\circ} \mathrm{C}$.

Dry tea sample preparation. A representative portion (10-20 g) of dried tea sample was ground. $1 \mathrm{~g}$ of tea powder was extracted with $10 \mathrm{ml}$ acetonitrile-water-formic acid $(80 / 20 / 0.5 \%$ vol.) by shaking and ultra sonicating for 30 minutes total; centrifuged for 10 minutes at $10,000 \mathrm{rpm}$. $1 \mathrm{ml}$ of supernatant was diluted with $1 \mathrm{ml}$ of the mobile phase A. After mixing, the diluted sample was centrifuged. $1.5 \mathrm{ml}$ of supernatant was transferred into a chromatographic vial for analysis.

Screening toxins production in vitro. The nutrient medium constituted of agar with streptomycin $(200 \mathrm{mg} / \mathrm{l})$ and $6 \%$ of ground dried tea as an only substrate. We used microbiologically clean green tea $(<10 \mathrm{CFU} / \mathrm{g}$ of mold fungi and bacteria), tested negative for MTs. The substrate was ground in a mill with sterile disposable grinding chambers and then aseptically added to melted hungry agar at $40 \pm 1{ }^{\circ} \mathrm{C}$. Washouts of dried tea samples $(10 \mathrm{~g}$ of tea in $90 \mathrm{ml}$ of a sterile phosphate buffer) were used as inoculates. $1 \mathrm{ml}$ of inoculates was placed into Petri dishes and imbedded with a nutrient medium. Cultivation lasted for ten days at $24^{\circ} \mathrm{C}$ in the dark. Next Petri dish contents (substrate mycelium) were thoroughly homogenized. $1 \mathrm{~g}$ of substrate mycelium obtained via this procedure was used for the extraction of mycotoxins.

Preparation of substrate mycelium samples for MTs analysis. $1 \mathrm{~g}$ of substrate mycelium was thoroughly mixed with $5 \mathrm{ml}$ of water-acetonitrileformic acid (refer to 'Dry tea sample preparation'). MTs were extracted in an ultrasound bath for 30 minutes and then centrifuged for $10 \mathrm{~min}$ utes at 4,000 rpm. After that $1 \mathrm{ml}$ of supernatant was diluted with $1 \mathrm{ml}$ of the mobile phase A, properly mixed and centrifuged for 10 minutes at $10,000 \mathrm{rpm} .1 .5 \mathrm{ml}$ of supernatant was transferred into a chromatographic vial for analysis.

Results results. Screening of mycotoxins in tea samples.

Screening of mycotoxins in tea samples. We examined MTs in samples of traditional unpacked loose $C$. sinensis tea from six tea- producing regions: China, India, Indonesia, Sri-Lanka, Vietnam, and Kenya. All but four samples from China were black teas. Eight of 29 analytes were detected, almost all below LOQ: AFLs group (AFL G2 and STC); trichothecenes (FusX, NeoS, T-2); Fusarium toxins (EnnB and BEA); MPA - a widely spread plant products contaminant (Table 3). 20 of 30 samples $(66.7 \%)$ were MTs positive. BEA was found in 18 samples out of $30(60 \%)$, occurrence of other MTs was much lower. Black tea samples from Vietnam and Indonesia were the most contaminated with MTs traces; then, in the descending order, tea samples from India, China, Kenya, and Sri-Lanka. Only one green tea sample from China was found to be positive for MTs. We did not detect any samples contaminated with regulated in tea AFL B1.

The results correlated with mycological studies of these samples [13]. Samples from Sri Lanka, Kenya and China characterized by low levels of mold contamination $\left(<10^{3} \mathrm{CFU} / \mathrm{g}\right)$ revealed low diversity of detected MTs. On the contrary, the higher diversity of detected MTs was noted for samples from Indonesia and India containing higher levels of mold ((1.5-2.3) $\left.10^{3} \mathrm{CFU} / \mathrm{g}\right)$. Samples from Vietnam were the exception: they proved to be microbiologically pure $\left(<10^{2} \mathrm{CFU} / \mathrm{g}\right)$, while number of detected MTs was comparable with that found for tea samples from Indonesia. The direct dependence of the content of MT and their producers was more characteristic of fresh samples. As storage proceeds, the viable forms of mold gradually die out. They are not detected within mycological analyses, while the MTs synthesized by them remain in tea.

Screening of MTs in samples of packed (loose and bagged) green and black C. sinensis tea and tea with additives revealed the occurrence of 12 MTs. Emergent MTs were detected in 20 of $24(83 \%)$ examined samples. BEA and MPA were the most frequent ones; they were detected in 13 out of 24 samples $(56 \%)$. AcDON and FusX were revealed in six and five samples correspondingly. NeoS, STC, Enn B, AME and TE were sporadic (Table 4). Contamination levels of BEA, MPA and TE in black and Pu'er tea were comparable with quantities occurring in other plant 
Table 3

MTs in unpacked loose $C$. sinensis tea samples from six tea-producing regions

\begin{tabular}{|c|c|c|c|c|c|c|c|c|c|c|c|c|c|c|c|c|c|c|c|c|c|c|c|c|c|c|}
\hline \multirow[t]{2}{*}{ Mycotoxin } & \multicolumn{4}{|c|}{$\begin{array}{c}\text { Vietnam, } \\
n=5\end{array}$} & \multicolumn{5}{|c|}{$\begin{array}{c}\text { Indonesia, } \\
n=5\end{array}$} & \multicolumn{4}{|c|}{$\begin{array}{l}\text { India, } \\
n=5\end{array}$} & \multicolumn{5}{|c|}{$\begin{array}{c}\text { China, } \\
n=5\end{array}$} & \multicolumn{4}{|c|}{$\begin{array}{c}\text { Sri-Lanka, } \\
n=5\end{array}$} & \multicolumn{4}{|c|}{$\begin{array}{c}\text { Kenya, } \\
n=5\end{array}$} \\
\hline & \begin{tabular}{|l|l|l}
1 & 1 \\
\end{tabular} & $2 \mid \begin{array}{l}2 \\
2\end{array}$ & 34 & 5 & 1 & 2 & 3 & 4 & 5 & 1 & $2 \mid 3$ & \begin{tabular}{|l|l|}
3 & 4 \\
\end{tabular} & 5 & 1 & & $3 *$ & $4 *$ & $5 *$ & 1 & $2 \mid 3$ & & \begin{tabular}{l|l}
4 & 5 \\
\end{tabular} & 1 & 2 & 3 & $4: 5$ \\
\hline \multicolumn{27}{|c|}{ MTs regulated in other food products } \\
\hline $\mathrm{T}-2$ & -1. & -+ & +- & - & - & - & -1 & - & + & - & -- & -- & - & - & - & - & - & - & -1 & $-1-$ & $-1-$ & $-{ }_{-}^{-}$ & - & - & -1 & $--1-$ \\
\hline \multicolumn{27}{|c|}{ Structure analogues of regulated MTs and emergent MTs: } \\
\hline AFL G2 & - & -- & -- & - & - & + & - & - & - & - & - & $-1-$ & - & - & - & - & - & - & -1 & - & - & - & - & - & - & - \\
\hline$\overline{\text { STC }}$ & + & -- & -- & - & + & + & - & - & - & - & - & -- & - & + & - & - & - & - & - & - & - & - & - & - & - & - \\
\hline FusX & - & -- & -+ & + & - & - & - & + & - & - & - & $-1+$ & + & - & - & - & - & - & - & - & - & -1 & - & + & - & - \\
\hline $\mathrm{NeoS}$ & + & -- & -- & - & - & - & - & - & - & - & - & -- & - & - & - & - & - & - & - & - & - & -- & - & - & - & - \\
\hline MPA & - & - & - & - & - & - & - & - & - & + & - & - & - & 20 & $0+$ & - & - & - & - & - & - & - & - & - & - & - \\
\hline EnnB & - & -+ & ++ & - & + & - & - & - & - & - & --1 & ++ & - & - & - & - & - & - & - & -- & -- & - & - & - & - & - \\
\hline BEA & + & ++ & ++ & & + & + & + & + & + & - & $-1-$ & ++ & + & + & + & - & - & - & + & + & - & - & + & - & - & -1 \\
\hline $\begin{array}{l}\text { Absolute } \\
\text { occur-rence } \\
\text { of MTs, cases }\end{array}$ & \multicolumn{4}{|c|}{12} & \multicolumn{5}{|c|}{11} & \multicolumn{4}{|c|}{8} & \multicolumn{5}{|c|}{5} & \multicolumn{4}{|c|}{2} & \\
\hline
\end{tabular}

Note: * - green tea samples are marked with;

"+" - MTs concentration is over LOD, but below LOQ;

"-“- MTs concentration is below LOD. The concentration of MPA in sample No1 from China is equal to $200 \mu \mathrm{g} / \mathrm{kg}$.

Table 4

MTs in packed (loose and bagged) C. sinensis tea samples

\begin{tabular}{|c|c|c|c|c|c|c|}
\hline \multirow{3}{*}{ Mycotoxins } & \multicolumn{6}{|c|}{ Packed tea samples ( $n-$ number of samples) } \\
\hline & $\begin{array}{l}\text { Green } \\
\text { loose, } \\
n=1\end{array}$ & $\begin{array}{c}\text { Green } \\
\text { bagged, } \\
\mid n=3\end{array}$ & $\begin{array}{l}\text { Black loose, } \\
\quad n=10\end{array}$ & $\begin{array}{c}\text { Black } \\
\text { bagged, } \\
n=6\end{array}$ & $\begin{array}{c}\text { Pu'er, } \\
n=2\end{array}$ & $\begin{array}{c}\text { Black with } \\
\text { thyme, bagged, } \\
\mid n=2\end{array}$ \\
\hline & \multicolumn{6}{|c|}{ Number of positive (>LOD) samples } \\
\hline Total positive & 1 & 3 & 7 & 6 & 2 & 1 \\
\hline \multicolumn{7}{|c|}{ MTs regulated in food products } \\
\hline AFL B1 & - & - & 1 & - & - & - \\
\hline T-2 & 1 & - & - & 1 & - & - \\
\hline \multicolumn{7}{|c|}{ Structure analogues of regulated MTs } \\
\hline AFL G2 & - & - & - & 1 & - & \\
\hline STC & - & - & 1 & - & - & $1(4.4 \mu \mathrm{g} / \mathrm{kg})^{*}$ \\
\hline AcDON & - & 2 & 3 & - & 1 & - \\
\hline FusX & - & - & 2 & 3 & - & - \\
\hline NeoS & - & - & 2 & - & - & - \\
\hline \multicolumn{7}{|c|}{ Emergent MTs } \\
\hline MPA & - & 3 & 4 & $\begin{array}{c}3 \\
(\leq 200 \mu \mathrm{g} / \mathrm{kg}) \\
\end{array}$ & $\begin{array}{c}2 \\
(\leq 3040 \mu \mathrm{g} / \mathrm{kg})\end{array}$ & 1 \\
\hline BEA & - & 2 & $4(\leq 6.0 \mu \mathrm{g} / \mathrm{kg})$ & 5 & 1 & 1 \\
\hline EnnB & - & - & - & - & - & 1 \\
\hline AME & - & 1 & - & - & - & - \\
\hline TE & - & - & - & $1(10)$ & - & - \\
\hline
\end{tabular}

Note: “_“-MTs were not detected (below LOD); * - concentration over LOQ is specified in brackets. 
commodities [7, 14]. Traces of AFLs were detected in two samples of black tea. STC was detected in two black tea samples (loose tea and bagged black tea with thyme). Its concentration in the latter sample was $4.4 \mu \mathrm{g} / \mathrm{kg}$. It should be noted, that STC is a biogenic precursor of hazardous AFL B1, and IARC lists it as a potential carcinogen [15].

Analysis of Pu'er tea samples did not reveal the expected variety of MTs; however, we should note that there were not enough analyzed samples to consider the obtained data applicable to the whole group of such products. Traditionally Pu'er is produced via extended fermentation of green tea that can last over 10 years; during this period, an initial microbiome is transformed, and it can create favorable conditions for accumulation of such MTs as patulin [16], AFL, DON [17], and OTA [18]. Hence it is not a coincidence that the first Pu'er brewing is not recommended for consumption. However, a traditional procedure is replaced with pile fermentation at present. It is less time consuming and lasts about 48 days [18]. Within the present study, one, about $3,040 \mu \mathrm{g} / \mathrm{kg}$ of MPA, was detected in one sample of Pu'er tea. MPA is produced by Penicillium spp. [19] and can accumulate in a product after harvesting in case storage conditions are improper [20]. Safety requirements for tea subjected to long fermentation, like Pu'er, are not defined clearly to-date. The microbiological standards recommended for teas by Tea \& Herbal Infusions Europe (THIE, 2018) do not cover Pu'er [21].

Thus, according to the microbiological survey reported in [13] and screening of MTs, all studied $C$. sinensis tea samples, including those with additives, meet the established MLs concerning fungal and MTs contamination.

Twelve samples of mono-component and 11 samples of and multi-component herbal tea samples were studied. Eight out of $12(66.6 \%)$ mono-component herbal teas (thyme, mint, Ivan-tea, and hibiscus tea) proved to be positive for ten out of 29 examined MTs (Table 5). Emergent MTs prevailed. The highest occurrence was noted for BEA and MPA; then, in descending order: EnnB and TE, AME, Enn A, DAS, FuzX and STC. As for MTs regulated in food products, two Ivan-tea samples were positive for DON ( $<$ LOQ). Thyme and Ivantea turned out to be the most contaminated. Thyme samples contained nine MTs that are not subjected to control. It was the highest diversity in mono-component herbal tea samples. Moreover, five of them were in quantities exceeding LOQs. Supposedly, thyme was the source of STC detected in bagged black tea with the addition of this herb (Table 4).

Table 5

MTs in mono-component herbal tea samples

\begin{tabular}{|c|c|c|c|c|}
\hline \multirow{3}{*}{ Mycotoxin } & \multicolumn{4}{|c|}{ Mono-component herbal tea } \\
\hline & Thyme, $n=4$ & Ivan-tea, $n=5$ & Mint, $n=2$ & Hibiscus, $n=1$ \\
\hline & \multicolumn{4}{|c|}{ Number of MT-positive (>LOD) samples } \\
\hline Total positive & 4 & 3 & 1 & - \\
\hline \multicolumn{5}{|c|}{ MTs regulated in food products } \\
\hline DON & - & 2 & - & - \\
\hline \multicolumn{5}{|c|}{ Structure analogues of regulated MTs } \\
\hline STC & $1(24 \mu \mathrm{g} / \mathrm{kg}) *$ & - & - & - \\
\hline FusX & 1 & - & - & - \\
\hline DAS & 1 & - & - & - \\
\hline \multicolumn{5}{|c|}{ Emergent MTs } \\
\hline MPA & $2(\leq 100 \mu \mathrm{g} / \mathrm{kg})$ & 2 & - & - \\
\hline BEA & $2(\leq 4 \mu \mathrm{g} / \mathrm{kg})$ & 1 & 1 & - \\
\hline EnnA & 1 & - & - & - \\
\hline EnnB & $2(\leq 26 \mu \mathrm{g} / \mathrm{kg})$ & 1 & - & - \\
\hline AME & 2 & - & 1 & - \\
\hline TE & $2(\leq 13 \mu \mathrm{g} / \mathrm{kg})$ & - & 1 & - \\
\hline
\end{tabular}

Note: “-“- MTs were not detected (below LOD); * - concentration over LOQ is specified in brackets. 
Microbiological testing of mono-component herbal tea samples [13] revealed that thyme and mint samples were the most contaminated with mold fungi. Two samples of thyme and two samples of mint herbal tea did not meet existing standards as mold fungi concentration reached $10^{5}$ and $10^{6} \mathrm{CFU} / \mathrm{g}$ correspondingly. All other samples proved to be safe. Ivan-tea samples provided interesting cases of fungi-bacteria competition. Low fungal contamination (about $50 \mathrm{CFU} / \mathrm{g}$ ) was coupled with high spore-forming bacteria concentration (up $10^{6-8} \mathrm{CFU} / \mathrm{g}$ ). Some spore-forming bacteria are known to be antagonistic to mold fungi. Their co-occurrence results in mutual competition for the substrate [22]. Thus, MTs found in Ivantea samples indicate that fungal contamination preceded bacterial. Therefore, low quantities or even absence of any viable mold fungi detected via mycological analysis do not necessarily mean that samples are MTs-negative.
On the other hand, pronounced fungal contamination usually implies MTs occurrence.

The group of multi-component herbal teas included 11 samples (Table 1). They proved to be highly contaminated with MTs: 10 (91\%) out of 11 samples were positive for 18 out of 29 examined analytes (Table 6). Six (54\%) samples contained seven or eight MTs simultaneously. MTs content was considerably higher in these samples than in any other examined in the present study. The most frequently detected emergent MTs were MPA and Alternaria metabolite TE. They were found in 7 out of 11 samples; BEA, EnnB and STC were detected in six samples; AME - in five; EnnA - in three; $\beta$-ZEL - in two samples. AFL G1, T-2-triol, DAS, ZEA, and FusX were detected sporadically. As opposed to other examined tea products, multi-component herbal tea samples contained a variety of regulated MTs such as AFLB1, OTA $(2 \mu \mathrm{g} / \mathrm{kg})$, DON,

Table 6

MTs in multi-component herbal tea samples

\begin{tabular}{|c|c|c|c|c|c|c|c|c|c|c|c|}
\hline \multirow[b]{2}{*}{ Mycotoxin } & \multicolumn{11}{|c|}{ Multi-component herbal tea } \\
\hline & No.14 & No.2 & No.36 & No.38 & No.20 & No.19 & No.8 & No.9 & No.10 & No.11 & No.12 \\
\hline \multicolumn{12}{|c|}{ MTs regulated in food products } \\
\hline AFLB1 & - & - & - & - & - & + & - & - & - & - & - \\
\hline OTA & - & - & - & - & - & $2.0^{*}$ & - & - & - & - & - \\
\hline DON & - & - & - & - & - & + & - & - & - & - & - \\
\hline $\mathbf{T}-\mathbf{2}$ & - & - & + & - & - & - & - & - & - & - & 9.2 \\
\hline FB2 & - & - & - & - & - & - & - & - & 100 & - & - \\
\hline ZEA & - & - & - & - & - & - & 190 & - & & - & - \\
\hline \multicolumn{12}{|c|}{ Structure analogues of regulated MTs } \\
\hline AFLG1 & - & - & - & - & - & 3.2 & - & - & - & - & - \\
\hline STC & - & - & - & - & - & + & 8.0 & + & 10.0 & 9.2 & 9.6 \\
\hline FusX & - & - & - & + & - & - & - & - & - & - & - \\
\hline $\mathrm{T}-2$ triol & - & - & - & - & - & - & - & - & - & - & + \\
\hline DAS & - & - & - & - & - & - & - & - & - & + & - \\
\hline$\beta$-ZEL & - & - & - & - & + & - & - & + & - & - & - \\
\hline \multicolumn{12}{|c|}{ Emergent MTs } \\
\hline MPA & - & - & + & + & + & + & 770 & 690 & 1760 & 440 & 2240 \\
\hline BEA & - & - & - & - & - & 20.4 & 6.0 & 5.6 & 5.6 & 8.0 & 8.0 \\
\hline EnnA & - & 2.8 & - & - & - & - & - & + & - & + & - \\
\hline EnnB & - & - & - & - & - & 13.6 & 22.4 & 52.0 & 34.0 & 55.0 & 36.0 \\
\hline TE & - & + & - & - & 5.6 & - & 6.0 & 5.2 & 5.2 & 9.2 & 6.4 \\
\hline AME & - & - & - & - & - & - & + & + & + & + & + \\
\hline
\end{tabular}

Note: "+" - MTs concentration is over LOD, but below LOQ; “_“- - MTs concentration is below LOD. ${ }^{*}$ - concentration exceeding LOQ is in $\mu \mathrm{g} / \mathrm{kg}$. 
T-2 $(9.2 \mu \mathrm{g} / \mathrm{kg})$, FB2 $(100 \mu \mathrm{g} / \mathrm{kg})$, ZEA $(190$ $\mu \mathrm{g} / \mathrm{kg})$. They occurred in quantities close to maximum levels (ML) set by regulations for food products in CU. Thus, five $\mu \mathrm{g} / \mathrm{kg}$ of OTA, $200 \mu \mathrm{g} / \mathrm{kg}$ of FBs and $50 \mu \mathrm{g} / \mathrm{kg}$ of T-2 toxin are MLs for these MTs in some cereals for children (CU TR 021/2011). Five $\mu \mathrm{g} / \mathrm{kg}$ of OTA is ML for coffee beans set in the EU.

Combined contamination of herbal tea samples with multiple MTs indicates that toxigenic fungi pounced on herbs both during vegetation, processing and storage. "Field fungi", such as Fusarium spp. are responsible for DON, T-2, T-2 triol, DAS, ZEN, b-ZEL, EnnA and B, BEA, FBs accumulation. Alternaria spp. also invade herbs "in fields" and produce AOH, AME, TE. "Storage" fungi are Aspergillus spp. (AFB1, AFG1, STC, OTA) and Penicillium spp. (MPA, OTA). This is following the results of the mycological study of these herbal tea samples [13].

Five samples of multi-component herbal teas (No. 8-12) turned out to contain from seven to eight different MTs together with high mold fungi contents $\left(10^{4}-10^{5} \mathrm{CFU} / \mathrm{g}\right)$. Eight MTs were detected in sample No. 19, meanwhile, fungal contamination was low (50 CFU/g). At the same time, the concentration of spore-forming bacteria was high $\left(8 \cdot 10^{5} \mathrm{CFU} / \mathrm{g}\right)$ in this sample. Similar results were obtained for Ivan-tea samples. They were discussed above in the paragraph, devoted to mono-component herbal tea. Sample No. 19 case also supports the idea that original mold fungal contamination was later suppressed by bacteria development. Therefore, even if a tea sample complies with the microbiological safety requirements fixed in the CU TR 021/2011, this does not mean that they do not contain MTs.

The increase in the number of detected MTs corresponded well with the growing number of components (see Tables 1 and 6). MTs variety in herbal tea was much higher as compared to $C$. sinensis tea samples. This is in accordance with literature data. For example, 12 MTs were discovered in 60 herbal tea samples marketed in Latvia. Co-occurrence of up to eight MTs was noted in $90 \%$ of the samples. EnnB, DON, AFB1, OTA, and ZEA were detected the most frequently [23]. Survey carried out in in Spain revealed $99 \%$ of 84 medical and aroma herbs samples were contaminated. OTA, FBs, AFLs, ZEA, T-2 toxin, DON and citrinin prevailed [24]. A wide variety of MTs was detected in meadow herbs and hay from European Russia regions: 16 MTs were detected including T-2, DAS, DON, ZEA, FBs, AOH, roridine A, AFL B1, STC, cyclopiazonic acid, emodin, OTA, citrinin, MPA, PR-toxin and ergot alkaloids [25].

Table 7 summarizes the occurrence of MTs in the examined $C$. sinensis and herbal tea samples. We detected emergent MTs in all kinds of studied tea. BEA, MPA, EnnB, TE, and FusX were detected the most frequently. We should note that structurally similar BEA and Enns are widely spread and occur in almost all types of plant raw materials and foods. For

Table 7

The occurrence of MTs in C. sinensis and herbal tea samples

\begin{tabular}{|c|c|c|c|}
\hline Tea & $\begin{array}{l}\text { MTs-positive } \\
\text { samples, } \%\end{array}$ & $\begin{array}{l}\text { Quantity of } \\
\text { detected MTs }\end{array}$ & Mycotoxins in decreasing order of occurrence \\
\hline $\begin{array}{l}\text { C. sinensis unpacked } \\
\text { (semi-finished) }\end{array}$ & 70 & 8 & $\begin{array}{l}\text { BEA }>\text { Fus X }>\text { EnnB }>\text { STC }>\text { MPA }>\text { T-2 }> \\
(\text { AFL G2, NeoS)* }\end{array}$ \\
\hline C. sinensis packed & 83 & 12 & $\begin{array}{l}(\mathrm{BEA}, \mathrm{MPA})>\text { AcDON }>\text { FusX }>(\mathrm{T}-2, \mathrm{NEOS})> \\
(\text { EnnB, AME, TE, STC, AFL B1 and G2) }\end{array}$ \\
\hline $\begin{array}{l}\text { Mono-component } \\
\text { herbal tea }\end{array}$ & 66.7 & 10 & $\begin{array}{l}(\text { BEA, MPA })>(\text { EnnB, AME, TE })>\text { DON }> \\
(\text { EnnA, DAS, FusX, STC })\end{array}$ \\
\hline $\begin{array}{l}\text { Multi-component } \\
\text { herbal tea }\end{array}$ & 91 & 18 & $\begin{array}{l}\text { MPA }>\text { TE }>(\text { BEA, EnnB, STC })>\text { AME }>\text { EnnA }> \\
(\text { T-2, } \beta \text {-ZEL })>\text { AFL B1 }>\text { AFL G1 }>(\text { DON, FB2, } \\
\text { OTA, T-2 triol, DAS, ZEA, FusX) }\end{array}$ \\
\hline
\end{tabular}

Note: MTs with equal occurrence are put in brackets. 
example, BEA was detected in $80 \%$ of tested food, while Enns - in $63 \%$. A risk assessment carried out by EFSA in 2014 demonstrated that there might be a concern with respect human health effects and chronic dietary exposure to BEA and Enns [9].

Although MTs are detected in low quantities, there is a potential risk that cumulative effects might appear. Toxic impacts that occur due to multiple mycotoxins being consumed simultaneously can become obvious both via additive effects and synergetic ones and in the latter case, overall toxicity can be higher than a simple sum of individual toxicities [26]. Additive effects are described for structurally similar compounds. Results obtained via research on individual and combined toxic effects produced by B-trichothecenes (DON, NIV, 3- and 15-AcDON, DON-3-glucoside and Fus-X) on epithelial cells in a human stomach (GES-1) allowed assuming that their simultaneous occurrence in food products even in low doses can be more or less toxic than a prediction based on data obtained for individual MTs [27]. The same goes for other structural MT analogues from the same species or family when their effects and toxicity profile are similar, for example, FBs or Enns. Synergic effects are described for OTA and AFLs; thus, low mortality due to mycotoxicosis caused by OTA grows considerably when it is combined with AFLs [28]. BEA, DON, and $\mathrm{T}-2$ produce high toxic effects and therefore, their combined exposure can induce certain diseases in people, especially in case exposure is long-term [29]. Overall, in most cases, a combined consumption of MTs results in additive or synergetic effects, and it causes more significant health risks for people and animals [30].

Nominally all the examined tea samples corresponded to hygienic standards. The concentration of AFLB1 did not exceed ML of $5 \mu \mathrm{g} / \mathrm{kg}$. Still, the co-occurrence of several MTs, especially highly toxic ones, in low doses can cause health risks for people in case of longterm exposure. The obtained data indicate the necessity to assess health risks associated with combined MTs contamination of food, in particular, plant raw materials used in manufactur- ing specialized food products for babies, dietary products, herbal food supplements, $C$. sinensis teas with additives, herbal tea, spices, etc.

Examination of toxin production by tea microflora in vitro. Contamination of traditional $C$. sinensis teas with mold fungi tends to be neglected, by regulatory authorities as well. This is often due to the fact that the risks caused by tea and tea raw materials being contaminated wuth MTs are rather low if production, transportation, and storage conditions correspond to the fixed humidity and temperature [31]. Another opinion is that the lack of growth factors and the content of polyphenolic compounds in tea prevent MTs production even in case there is high mold contamination [32]. Nevertheless, the results of studies of tea samples from various regions confirm that hazardous MTs such as FB, OTA, AFL, T-2, ZEA can be detected in such products in large quantities [11]. For example, $82 \%$ black and green tea samples obtained from retail outlets in Italy were contained OTA, and in $50 \%$ cases its quantity amounted to 7-21 $\mu \mathrm{g} / \mathrm{kg}$ (with predominant A. niger and A. tubingensis). These concentrations exceeded the MLs set for other food products, the consumption volumes of which are comparable to teas, in particular, coffee $(5 \mu \mathrm{g} / \mathrm{kg})$ [33]. Research performed in Switzerland revealed that black mold fungi were one of the most widely-spread ones in 22 samples of herbal teas and isolated strains of A. niger and A. awamori produced FBs in vitro [34]. Several studies have reported the production of toxins in vitro on several types of model culture media by certain strains of Aspergillus sp. and Fusarium sp. which were isolated from plant raw materials including tea made of medicinal herbs [34-36]. The results of these studies show that the types and levels of MTs accumulation by producing fungi in model nutrient media are substrate-specific and do not always reflect toxin production in natural conditions adequately. In nature, different mold fungi compete with each other and exometabolites (MTs) are their weapon used in fighting for a substrate.

We examined a possibility of MTs producing directly in tea substrate in vitro under 
conditions closest to reality with excess humidity. Green tea was the only substrate, and MTs producers were a consortium of mold fungi that naturally present in certain tea samples. To do that, we selected tea samples with the highest contamination from those previously examined ones; they were multi- and mono-component teas contaminated with mold fungi in quantities equal to $10^{3}-7 \cdot 10^{4} \mathrm{CFU} / \mathrm{g}$ which was higher than MLs. We made washouts out of them (a part of tea and 9 parts of water); wash-outs were used to inoculate an agarized nutrient medium with green $C$. sinensis tea. We used sterile water as an inoculate in a reference sample. Incubation lasted for ten days; then MT were extracted from the substrate and analyzed.

As a result, we revealed that MTs, emergent alongside with regulated ones, which had not been detected in initial dry tea samples, accumulated in extracts from a nutrient medium. Their production was up to: FB1 -
$294 \mu \mathrm{g} / \mathrm{g} ;$ FB2 - 4.8-5,694 $\mu \mathrm{g} / \mathrm{g} ; \mathbf{Z E A}-$ $128 \mu \mathrm{g} / \mathrm{g} ;$ STC $-14.4 \mu \mathrm{g} / \mathrm{g}$; EnnB $-1.8 \mu \mathrm{g} / \mathrm{g}$; BEA - 1.36-9.0 $\mu \mathrm{g} / \mathrm{g}$; MPA - 23-303 $\mu \mathrm{g} / \mathrm{g}$; AME $-158 \mu \mathrm{g} / \mathrm{g}$ of a nutrient medium (Table 8).

Obtained results confirmed that toxigenic species of molds from tea samples are capable of accumulating different types of MTs, including emergent ones, simultaneously. It is possible under favourable conditions (humidity - temperature) in a plant substrate with tea leaves as the only nutrient component. This supports the idea that fungal contamination of C. sinensis can result in contamination of teas with MTs.

Conclusions. $C$. sinensis and herbal tea samples were screened for 29 MTs. The results revealed that black and green C.sinensis tea samples, both bought in retail outlets and obtained from wholesalers, were contaminated with mycotoxins only at low (trace) quantities. A much wider spectrum of MTs, including regulated in other kind of food and emergent,

Table 8

MT production by mold fungi contaminants of selected tea samples in vitro

\begin{tabular}{|c|c|c|c|}
\hline \multirow{2}{*}{$\begin{array}{l}\text { Sample } \\
\text { No. }\end{array}$} & \multirow{2}{*}{ Species of viable mold fungi in initial dry tea samples [13] } & \multicolumn{2}{|c|}{$\begin{array}{l}\text { Mycotoxins detected } \\
\text { in a nutrient medium in vitro }\end{array}$} \\
\hline & & Content, $\mu \mathrm{g} / \mathrm{kg}$ & $<$ LOQ (traces) \\
\hline 2 & $\begin{array}{l}\text { Aspergillus sections Nigri, Mucor sp., Fusarium sp., Alter- } \\
\text { naria sp. }\end{array}$ & EnnB-1.8 & TE \\
\hline 3 & $\begin{array}{l}\text { Aspergillus sp., Penicillium sp., Mucor sp., Fusarium sp., } \\
\text { Alternaria sp. }\end{array}$ & BEA-9.0 & AME \\
\hline 4 & $\begin{array}{l}\text { Aspergillus sections Nigri,Mucor sp., Fusarium sp., Alter- } \\
\text { naria sp. }\end{array}$ & $\begin{array}{c}\text { FB1-294; FB2-218; } \\
\text { ZEA-128 }\end{array}$ & BEA \\
\hline 5 & $\begin{array}{l}\text { Aspergillus sections Nigri, Mucor sp., Penicillium } \\
\text { sp.,Fusarium sp., Alternaria sp. }\end{array}$ & FB2-952 & $\begin{array}{c}\text { STC, T-2, BEA, } \\
\text { DAS }\end{array}$ \\
\hline 6 & Aspergillus sections Nigri, Mucor sp., Alternaria sp. & STC-14.4; FB2-4.8 & $\beta$-ZEL, AME \\
\hline 7 & $\begin{array}{l}\text { Penicillium sp., Aspergillus sp., Aspergillus sections Nigri, } \\
\text { Mucor sp., Epicoccus sp., Fusarium sp., Alternaria sp. }\end{array}$ & MPA-23 & $\begin{array}{l}\text { AFLB1, BEA, } \\
\text { T-2 }\end{array}$ \\
\hline 8 & $\begin{array}{l}\text { Aspergillus sections Nigri, Mucor sp., Fusarium sp., } \\
\text { Penicillium sp.,Alternaria sp. }\end{array}$ & BEA-1.36 & - \\
\hline 9 & $\begin{array}{l}\text { Penicillium sp.,Aspergillus sections Nigri, Aspergillus sp., } \\
\text { Mucor sp., Fusarium sp. Alternaria sp. }\end{array}$ & $\begin{array}{l}\text { FB2-5,624; } \\
\text { MPA-303 }\end{array}$ & $\begin{array}{l}\text { EnnA and B, } \\
\text { BEA }\end{array}$ \\
\hline 10 & $\begin{array}{l}\text { Penicillium sp.,Aspergillus sections Nigri, Aspergillus sp., } \\
\text { Fusarium sp. }\end{array}$ & MPA-45 & - \\
\hline 11 & $\begin{array}{l}\text { Penicillium sp.,Aspergillussp., Aspergillus sections Nigri, } \\
\text { Mucor sp.,Fusarium sp. Epicoccussp.,Alternaria sp. }\end{array}$ & AME-158 & BEA \\
\hline 12 & $\begin{array}{l}\text { Aspergillus sections Nigri, Aspergillus sp., Penicillium } \\
\text { sp.,Mucor sp., Fusarium sp. }\end{array}$ & - & AFLB1, BEA \\
\hline Substrate & Not detected & - & - \\
\hline
\end{tabular}

Note: Substrate: "clean” C. sinensis green tea; “-“- MTs were not detected ( $<$ LOD). 
was detected in herbal tea samples. Twelve MTs were detected in quantities over LOQs. Neither of 77 samples contained AFLB1 in quantities higher than fixed standards $(<5 \mu \mathrm{g} / \mathrm{kg})$.

Co-occurrence of regulated and emergent MTs in C. sinensis and herbal teas can be a potential health hazard under long-term exposure taking into account cumulative effects even at low levels. More representative monitoring and data accumulation is essential for assessing health risks associated with MTs in such products.

Comparison of fungal and mycotoxin contamination in the studied tea samples revealed that low fungal contamination doesn't necessarily mean the absence of mycotoxins. Conversely, an increase in the number and variety of fungal species leads to a greater variety of metabolites.

Toxigenic properties of microflora that occurred in teas were examined in vitro in condi- tions that were as close to real ones as it was only possible; we applied green C.sinensis tea leaves as a substrate. Our experiment confirmed the ability of toxigenic mold fungi to accumulate different types of MTs and EMTs simultaneously in significant amounts comparable to MLs established for foods of plant origin $(\mu \mathrm{g} / \mathrm{kg})$ : FB1-294 $\mu \mathrm{g} / \mathrm{kg}$; FB2-5,624 $\mu \mathrm{g} / \mathrm{kg} ;$ ZEN-128 $\mu \mathrm{g} / \mathrm{kg} ;$ STC-14.4 $\mu \mathrm{g} / \mathrm{kg}$; AME $-158 \mu \mathrm{g} / \mathrm{kg}$.

Funding. This research has been accomplished due to support provided within a grant by the Russian science foundation (Project No. 18-16-00077) "Emergent mycotoxins in vegetable food products: working out analysis procedures, examining contamination, drawing up a stem characteristics of micromycetes - producers, working out hygienic standards."

Conflict of interests. The authors declare no conflicts of interests.

\section{References}

1. Worldwide regulations for mycotoxins in foods and feeds in 2003. Food and Agriculture Organization (FAO). FAO Food and Nutrition Paper 81, Rome, Italy, 2004. Available at: http: //www.fao.org/3/y5499e/y5499e00.htm (20.11.2019).

2. Logrieco A.F., Miller J.D., Eskola M., Krska R., Ayalew A., Bandyopadhyay R., Battilani P., Bhatnagar D. [et al.]. The Mycotox Charter: Increasing Awareness of, and Concerted Action for, Minimizing Mycotoxin Exposure Worldwide. Toxins, 2018, vol. 10, no. 149, pp. E149. DOI: 10.3390/toxins 100401493

3. Njumbe Ediage E., Van Poucke C., De Saeger S. A multi-analyte LC-MS/MS method for the analysis of 23 mycotoxins in different sorghum varieties: the forgotten sample matrix. Food chemistry, 2015 , vol. 15, no. 177, pp. 397-404. DOI: 10.1016/j.foodchem.2015.01.060

4. García-Moraleja A., Font G., Mañes J., Ferrer E. Development of a new method for the simultaneous determination of 21 mycotoxins in coffee beverages by liquid chromatography tandem mass spectrometry. Food Research International, 2015, vol. 72, pp. 247-255. DOI: 10.1016/j.foodres.2015.02.030

5. Abdallah M.F., Krska R., Sulyok M. Occurrence of Ochratoxins Fumonisin B2 Aflatoxins (B1 and B2) and Other Secondary Fungal Metabolites in Dried Date Palm Fruits from Egypt: A MiniSurvey. Journal of food science, 2018, vol. 83, no. 2, pp. 559-564. DOI: 10.1111/1750-3841.14046

6. Juan C., Covarelli L., Beccari G., Colasante V., Manes J. Simultaneous analysis of twentysix mycotoxins in durum wheat grain from Italy. Food Control, 2016, vol. 62, pp. 322-329. DOI: 10.1016/j.foodcont.2015.10.032

7. Fraeyman S., Croubels S., Devreese M., Antonissen G. Emerging Fusarium and Alternaria Mycotoxins: Occurrence, Toxicity and Toxicokinetics. Toxins, 2017, vol. 18, no. 9 (7), pp. E228. DOI: $10.3390 /$ toxins 9070228

8. Scientific Opinion on the risks for animal and public health related to the presence of Alternariatoxins in feed and food. EFSA Journal, 2011, vol. 9, no. 10, pp. 2407. DOI: 10.2903/j.efsa.2011.2407

9. Scientific Opinion on the risks to human and animal health related to the presence of beauvericin and enniatins in food and feed. EFSA Journal, 2014, vol. 12, no. 8, pp. 3802. DOI: 10.2903/j.efsa.2014.3802

10. Sedova I.B., Kiseleva M.G., Zakharova L.P., Tutel'yan V.A. Toxicological and hygienic characteristics of mycotoxin sterigmatocystin and methods for its determination in food products. Gigiena $i$ sanitariya, 2019, vol. 98, no. 1, pp. 105-117 (in Russian). 
11. Sedova I., Kiseleva M., Tutelyan V. Mycotoxins in Tea: Occurrence, Methods of Determination and Risk Evaluation. Toxins, 2018, vol. 10, no. 11, pp. 444. DOI: 10.3390/toxins10110444

12. Rocha-Miranda F., Venancio A. Mycotoxigenic fungi in plant-based supplements and medicines. Current Opinion in Food Science, 2019, vol. 30, pp. 27-31. DOI: 10.1016/j.cofs.2018.08.003

13. Minaeva L.P., Aleshkina A.I., Markova Y.M., Polyanina A.S., Pichugina T.V., Bykova I.B., Stetsenko V.V., Efimochkina N.R., Sheveleva S.A. Studying the contamination of tea and herbal infusions with mold fungi as potential mycotoxin producers: The first step to risk assessment (Message 1). Health Risk Analysis, 2019, no. 1, pp. 93-102 (in Russian). DOI: 10.21668/health.risk/2019.1.10.eng

14. Han X., Xu W., Zhang J., Xu J., Li F. Co-Occurrence of Beauvericin and Enniatins in Edible Vegetable Oil Samples, China. Toxins, 2019, vol. 11, no. 2, pp. 100. DOI: 10.3390/toxins1 1020100

15. IARC Monographs on the Evaluation of Carcinogenic Risks to Humans. Volume 56. Some Naturally Occurring Substances: Food Items and Constituents, Heterocyclic Aromatic Amines and Mycotoxins. International Agency for Research on Cancer, Lyon, France, 1993, 609 p.

16. Zhang Y., Skaar I., Sulyok M., Liu X., Rao M., Taylor J.W. The Microbiome and Metabolites in Fermented Pu-erh Tea as Revealed by High-Throughput Sequencing and Quantitative Multiplex Metabolite Analysis. PLoS ONE, 2016, vol. 11, pp. e0157847. DOI: 10.1371/journal.pone.0157847

17. Wu J.-Y., Yang G.-Y., Chen J.-L., Li W.-X., Li J.-T., Fu C.-X., Jiang G.-F., Zhu W. Investigation for Pu-erh tea contamination caused by mycotoxins in a tea market in Guangzhou. J. Basic Appl. Sci, 2014, vol. 10, pp. 349-356. DOI: 10.6000/1927-5129.2014.10.46

18. Haas D., Pfeifer B., Reiterich C., Partenheimer R., Reck B., Buzina W. Identification and quantification of fungi and mycotoxins from Pu-erh tea. Int. J. Food Microbiol, 2013, vol. 166, pp. 316-322. DOI: $10.1016 /$ j.ijfoodmicro.2013.07.024

19. Vinokurova N.G., Ivanushkina N.E., Kochkina G.A., Arinbasarov M.U., Ozerskaya S.M. Production of Mycophenolic acid by fungi of the genus Penicillium Link. Prikladnaya biokhimiya i mikrobiologiya, 2005, vol. 41, no. 1, pp. 95-98 (in Russian).

20. Burkin A.A., Kononenko G.P. Producers of mycophenolic acid in ensiled and grain feeds. Applied Biochemistry and Microbiology, 2010, vol. 46, no. 5, pp. 545-550. DOI: 10.1134/S0003683810050145

21. Compendium of Guidelines for Herbal and Fruit Infusions. Tea \& Herbal Infusions Europe (THIE). Available at: http://www.thie-online.eu/fileadmin/inhalte/Publications/HFI/2018/20180717_Compendium_of_Guidelines_for_Herbal_Infusions_-_ISSUE_6.pdf (26.11.2019).

22. Venkatesh N., Keller N.P. Mycotoxins in Conversation with Bacteria and Fungi. J. Front Microbiol, 2019, vol. 10, pp. 403. DOI: 10.3389/fmicb.2019.00403

23. Reinholds I., Bogdanova E., Pugajeva I., Bartkevics V. Mycotoxins in herbal teas marketed in Latvia and dietary exposure assessment. J. Food Additives \& Contaminants: Part B, 2019, vol. 12, no. 3, pp. 199-208. DOI: 10.1080/19393210.2019.1597927

24. Santos L., Marın S., Sanchis V., Ramos A.J. Screening of mycotoxin multicontaminationin medicinal and aromatic herbs sampled in Spain. J. Sci Food Agric, 2009, vol. 89, pp. 1802-1807. DOI: $10.1002 /$ jsfa.3647

25. Burkin A.A., Kononenko G.P. Mycotoxin contamination of meadow grasses in European Russia. Sel'skokhozyaistvennaya biologiya, 2015, vol. 50, no. 4, pp. 503-512 (in Russian). DOI: 10.15389/agrobiology.2015.4.503rus

26. Speijers G.J.A., Speijers M.H.M. Combined toxic effects of mycotoxins. J. Toxicol Lett, 2004, vol. 153, pp. 91-98. DOI: 10.1016/j.toxlet.2004.04.046

27. Yang Y., Yu S., Tan Y., Liu N., A. Wu. Individual and Combined Cytotoxic Effects of CoOccurring Deoxynivalenol Family Mycotoxins on Human Gastric Epithelial Cells. J. Toxins (Basel), 2017, vol. 9, no. 3, pp. 96. DOI: 10.3390/toxins9030096

28. Hou L.L., Zhou X., Gan F., Liu Z.X., Zhou Y.J., Qian G., Huang K. Combination of selenomethionine and $\mathrm{N}$-acetylcysteine alleviates the joint toxicities of aflatoxin B1 and ochratoxin A by ERK MAPK signal pathway in porcine alveolar macrophages. J. Agric. Food Chem, 2018, vol. 66, no. 23, pp. 5913-5923. DOI: 10.1021/acs.jafc.8b01858

29. Ruiz M.J., Franzova P., Juan-García A., Font G. Toxicological interactions between the mycotoxins beauvericin, deoxynivalenol and T-2 toxin in CHO-K1 cells in vitro. Toxicon, 2011, vol. 58, no. 4, pp. 315-326. DOI: 10.1016/j.toxicon.2011.07.015 
30. Smith M.C., Madec S., Coton E., Hymery N. Natural Co-Occurrence of Mycotoxins in Foods and Feeds and Their in Vitro Combined Toxicological Effects. Toxins (Basel), 2016, vol. 8, no. 4, pp. 94. DOI: $10.3390 /$ toxins 8040094

31. Opinion on the potential microbiological risk arising from the presence of moisture in tea. Scientific Committee on Foods, European Union, 2016. Available at: http: //www.thie-online.eu/tea/qualityassurance/ (26.11.2019).

32. Mo H.Z., Zhang H., Wu Q.H., Hu L.B. Inhibitory effects of tea extract on aflatoxin production by Aspergillus flavus. Lett. Appl. Microbiol, 2013, vol. 56, pp. 462-466. DOI: 10.1111/lam.12073

33. Carraturo F., De Castro O., Troisi J., De Luca A., Masucci A., Cennamo P., Trifuoggi M., Aliberti F. Comparative assessment of the quality of commercial black and green tea using microbiology analyses. BMC Microbiology, 2018, vol. 18, no. 1, pp. 4. DOI: 10.1186/s12866-017-1142-z

34. Storari M., Dennert F.G., Bigler L., Gessler C., Broggini G.A.L. Isolation of mycotoxins producing black aspergilli in herbal teas available on the Swiss market. Food Control, 2012, vol. 26, pp. 157-161. DOI: 10.1016/j.foodcont.2012.01.026

35. Shi W., Tan Y., Wang S., Gardiner D.M., De Saeger S., Liao Y., Wang C., Fan Y., Wang Z., Wu A. Mycotoxigenic Potentials of Fusarium Species in Various Culture Matrices Revealed by Mycotoxin Profiling. Toxins, 2017, vol. 9, no. 1, pp. 6. DOI: 10.3390/toxins9010006

36. Mogensen J.M., Nielsen K.F., Samson R.A., Frisvad J.C., Thrane U. Effect of temperature and water activity on the production of fumonisins by Aspergillus niger and different Fusarium species. BMC Microbiol, 2009, vol. 31, no. 9, 281 p. DOI: 10.1186/1471-2180-9-281

Abbreviations: alternariol (AOH); aflatoxins B1, B2, G1 and G2 (AFLB1, B2, G1 and G2); 3- and 15-acetyldeoxynivalenol (3- and 15-AcDON); beauvericin (BEA); deoxynivalenol (DON); diacetoxyscirpenol (DAS); $\alpha$-zearalanol (zeranol, $\alpha$-ZAL); $\beta$-zearalanol (taleranol, $\beta$-ZAL); $\alpha$ - and $\beta$-zearalenol ( $\alpha$ - and $\beta$-ZEL); zearalenone (ZEA); mycophenolic acid (MPA); alternariol methyl ether (AME); moniliformin (MO); neosolaniol (NeoS); nivalenol (NIV); sterigmatocystin (STC); tentoxin (TE); T-2 (T-2 toxin); HT-2 (HT-2 toxin); T-2 triol (T-2 triol); fusarenone X (4-acetyl nivalenol, FusX); fumonisins B1 and $\mathrm{B} 2$ (FB1 and FB2); enniatins A and B (Enn A and B).

Kiseleva M.G., Chalyy Z.A., Sedova I.B., Minaeva L.P., Sheveleva S.A. Studying the contamination of tea and herbal infusions with mycotoxins (Message 2). Health Risk Analysis, 2020, no. 1, pp. 38-51. DOI: 10.21668/health.risk/2020.1.04.eng

Received: 28.11.2019

Accepted: 03.02.2020

Published: 30.03.2020 